\title{
Phenotypic Variability and Incomplete Penetrance of Spontaneous Fractures in an Inbred Strain of Transgenic Mice Expressing a Mutated Collagen Gene (COL1A1)
}

\author{
Ruth Pereira, Kenneth Halford, Boris P. Sokolov, Jaspal S. Khillan, and Darwin J. Prockop \\ Department of Biochemistry and Molecular Biology, Jefferson Institute of Molecular Medicine, Jefferson Medical College, \\ Thomas Jefferson University, Philadelphia, Pennsylvania 19107
}

\begin{abstract}
Phenotype variability and incomplete penetrance are frequently observed in human monogenic diseases such as osteogenesis imperfecta. Here an inbred strain of transgenic mice expressing an internally deleted gene for the proal (I) chain of type I procollagen (COL1A1) was bred to wild type mice of the same strain so that the inheritance of a fracture phenotype could be examined in a homogeneous genetic background. To minimize the effects of environmental factors, the phenotype was evaluated in embryos that were removed from impregnated females $1 \mathrm{~d}$ before term. Examination of stained skeletons from 51 transgenic embryos from 11 separate litters demonstrated that $\sim 22 \%$ had a severe phenotype with extensive fractures of both long bones and ribs, $\sim 51 \%$ had a mild phenotype with fractures of ribs only, and $\sim 27 \%$ had no fractures. The ratio of steady-state levels of the mRNA from the transgene to the level of mRNA from the endogenous gene was the same in all transgenic embryos. The results demonstrated that the phenotypic variability and incomplete penetrance were not explained by variations in genetic background or levels in gene expression. Instead, they suggested that phenotypic variation is an inherent feature of expression of a mutated collagen gene. (J. Clin. Invest. 1994. 93:1765-1769.) Key words: osteopenia • gene expression • predisposition to fractures
\end{abstract}

\section{Introduction}

Phenotypic variability and incomplete penetrance are frequently observed in monogenic diseases in humans (see references 1 and 2 ). The phenomena are usually explained by differences in genetic background or environmental factors. However, the same phenomena are frequently seen with mutations in simpler organisms with homogeneous genetic backgrounds and in whom environmental factors can be rigorously controlled. For example, two different dominant negative alleles of let-60 locus in Caenorhabitis elegans produced variable pene-

Address correspondence to Dr. Darwin J. Prockop, Department of Biochemistry and Molecular Biology, Jefferson Institute of Molecular Medicine, Jefferson Medical College, Thomas Jefferson University, Philadelphia, PA 19107.

Received for publication 16 August 1993 and in revised form 10 December 1993.

J. Clin. Invest.

(c) The American Society for Clinical Investigation, Inc.

0021-9738/94/04/1765/05 \$2.00

Volume 93, April 1994, 1765-1769 trance of a vulvaless phenotype so that about half of the progeny who inherited one of the mutated alleles were eggless, whereas about half were not (3). As another example, similar marked variations in phenotype were seen in the same organism with several mutations in the unc-5, unc-6, and unc-40 genes that guide circumferential migrations of pioneer axons and mesodermal cells (4).

Of special interest to us has been the phenotypic variation and incomplete penetrance seen in some families with osteogenesis imperfecta. For example, de Vries and de Wet (5) reported on a family in which three affected members of the first and third generations were of short stature and had multiple fractures and skeletal deformities. The family member from the second generation who transmitted the disease, however, was of normal stature and had no evidence of either fractures or skeletal deformities. Similarly, Sippola et al. (6) described a large three-generation family in which nine affected members had a variable phenotype in that some had only slightly short stature and blue sclerae, whereas others had multiple fractures and permanent dislocations of large joints.

To explore the causes of incomplete penetrance and phenotypic variation seen with mutated collagen genes, we examined here an inbred strain of transgenic mice $(7,8)$ expressing an internally deleted gene for the pro $\alpha 1$ (I) chain of type I procollagen (COL1A1). The construct was designed so as to cause synthesis of shortened pro $\alpha 1$ (I) chains that associated with normal pro $\alpha 1$ (I) chains from the endogenous mouse gene. The association of the chains caused degradation of both the normal and the mutated chains through a phenomenon referred to as procollagen suicide or as a dominant negative effect (9). As previously reported $(7,8)$, lines of mice expressing high levels of the internally deleted gene developed a lethal phenotype with multiple fractures and other features similar to probands with lethal variants of osteogenesis imperfecta. Lines of mice expressing lower levels of the same gene were either phenotypically normal or had a milder phenotype. The results here demonstrate that an inbred line of transgenic mice expressing a moderate level of the mutated gene produces a variable phenotype of fractures even in embryos examined in utero.

\section{Methods}

Preparation and breeding of transgenic mice. Transgenic mice were prepared in an inbred strain of mice (FVB/N) as described previously (7). To identify transgenic mice, genomic DNA was extracted from tissues by digestion with proteinase $\mathrm{K}$, extraction with phenol:chloroform:isoamyl alcohol, and ethanol precipitation. Because the copy number in the line was $>15$, the presence or absence of the transgene was readily detected by slot blotting of the DNA with a probe that consisted of the nick-translated ${ }^{32} \mathrm{P}$-radiolabeled transgene (7). 
Skeletal staining. To define the phenotypes of the transgenic mice, viscera and skin were removed and the mouse carcasses were fixed in $95 \%$ ethanol for $3 \mathrm{~d}$. The samples were then dehydrated in $100 \%$ ethanol for $2 \mathrm{~d}$. They were immersed in $1 \% \mathrm{KOH}$ for $1 \mathrm{~d}$ to dissolve the soft tissues and the skeletons were stained with $1 \% \mathrm{KOH}$ containing $0.001 \%$ Alizarin red S for $1 \mathrm{~d}(10)$. The samples were incubated with 25,50 , and $80 \%$ glycerol for $1 \mathrm{~d}$ each and stored in $100 \%$ glycerol. The presence of fractures in the skeletons was assessed by light microscopy.

Assays of levels of expression. To assay the steady-state levels of mRNA, total cellular RNA was isolated from tissues by extraction with acidic guanidinium thiocyanate-phenol-chloroform (11). The amount of mRNA from the transgene relative to the mouse mRNA from endogenous COL1A 1 gene was measured by a quantitative reverse transcriptase (RT)-PCR method (12). 1-5 $\mu \mathrm{g}$ of total RNA was reverse transcribed in $20 \mu$ l of reaction mixture using primer BS33 (5'-ATCAAGTTTGA' $\left.3^{\prime}\right)(200$ pmol $)$ for the pro $\alpha 1$ (I) chain and a preamplification system for first-strand cDNA synthesis (SuperScript ${ }^{\circledR}$, GIBCO BRL, Gaithersburg, MD). The sample was treated with $\mathrm{RNase} H$ and the cDNA was amplified directly using a PCR reagent kit (GeneAmp ${ }^{\oplus}$, Perkin-Elmer Cetus, Cochranville, PA), and primers BS31 (5'-TTGGCCCTGTCTGCTT-3') and BS32 (5'-TGAATGCAAAGGAAAAAAAT-3') using 4 pmol of each in a $100-\mu$ l reaction mixture (12). One of the primers used in the PCR was 5 ' end labeled with $\left[{ }^{32} \mathrm{P}\right] \mathrm{dATP}$ using T4 polynucleotide kinase terminus labeling system (GIBCO BRL). PCR conditions were $80 \mathrm{~s}$ at $94^{\circ} \mathrm{C}, 1 \mathrm{~min}$ at $47^{\circ} \mathrm{C}$, and $20 \mathrm{~s}$ at $72^{\circ} \mathrm{C}$ for 15 cycles. After the PCR, $5 \mu$ l of reaction mixture was digested with $12 \mathrm{U}$ of BstNI for $15 \mathrm{~h}$ at $60^{\circ} \mathrm{C}$. $10 \mu \mathrm{l}$ of the product was denatured and subjected to electrophoresis in 15\% PAGE containing $6 \mathrm{M}$ urea. The gel was fixed and dried. The appropriate bands on the gel were then assayed by exposing the gel to a photostimulable storage phosphor imaging plate (400S PhosphorImager; Molecular Dynamics, Sunnyvale, CA). As reported previously (12), the assay was linear when carried out with standard samples in which the ratio of mRNA from the transgene and the endogenous gene varied from 0.1 to 1.0.

Assay of mineral content of embryos. After the stained skeletons were evaluated microscopically, the same samples were taken for assay of mineral content. The samples were wrapped in aluminum foil and reduced to mineral by heating at $600^{\circ} \mathrm{C}$ in an insulated oven (Type 1400 furnace; Barnstead-Thermolyne; Dubuque, IA) for $18 \mathrm{~h}$, after which they were weighed again. Because the small amounts of glycerol in the samples ignited during the first few minutes at $600^{\circ} \mathrm{C}$, the oven was placed in a fume hood. Preliminary experiments indicated there was no further decrease in weight if samples were incubated at $600^{\circ} \mathrm{C}$ for $>18 \mathrm{~h}$.

\section{Results}

Evaluation of phenotype in transgenic mice. The transgenic mice were prepared with an internally deleted construct of the human gene for the pro $\alpha 1$ (I) chain of type I procollagen (9). The gene construct contained $2.3 \mathrm{~kb}$ of the promoter and $2 \mathrm{~kb}$ of the 3 -flanking sequence. Intron 5 of the gene was joined to intron 46 so that there was an in-frame deletion of exons 6-46. The line selected for study here (line $\mathrm{V}$ in reference 7 ) expressed moderate levels of the transgene. Ultrastructural data on the line were recently reported (13).

To obtain embryos for analysis here, transgenic males from generations III, IV, and V (Fig. 1) were bred to wild type females from the same inbred strain. Embryos were removed from impregnated females $18 \mathrm{~d}$ after the vaginal plug was seen and, therefore, $1 \mathrm{~d}$ before expected normal delivery. The skeletons were stained and examined microscopically. Some of the mice had a severe phenotype with extensive fractures of both long bones and ribs (Fig. 2 left). Other mice had a mild phenotype with fractures of ribs but not any long bones (Fig. 2 right). Still other mice had no evidence of fractures. As indicated in Table I, 51 transgenic embryos from 11 separate litters were examined. About $22 \%$ had the severe phenotype, $\sim 51 \%$ had the mild phenotype, and $\sim 27 \%$ had a normal phenotype.

Level of expression of the transgene. To determine whether the variability of phenotype was related to level of expression in the transgene, mRNA from tissues of the embryos was assayed by a quantitative RT-PCR method. The method used identical primers for both the human transgene and the endogenous mouse gene, but DNA fragments of different size were obtained after cleavage with the restriction endonuclease BstNI (12). As indicated in Fig. 3, the fragments from the PCR products from the transgene and the endogenous gene were readily distinguished by polyacrylamide gel electrophoresis. The ratio of the two fragments was used as a measure of the level of expression of the transgene relative to expression of the endogenous gene. As indicated in Table II, there were no significant differences in the ratios of the mRNAs among mice that had the severe phenotype, the mild phenotype, and a normal phenotype.

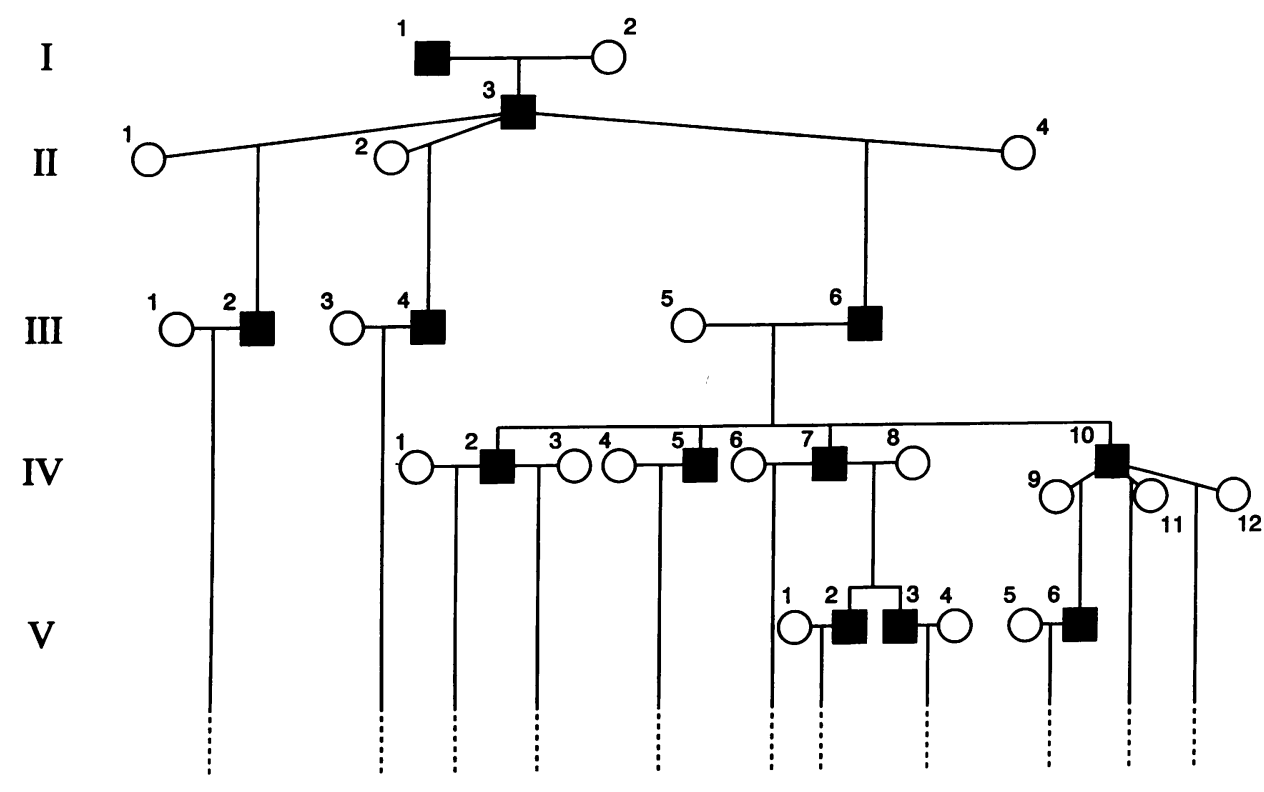

Figure 1. Scheme for matings of the transgenic mice. For examination of phenotypic variation in 18-d-old transgenic embryos, cesarean sections were performed on the mating described here as generations III, IV, and V. (a) Transgenic males. 

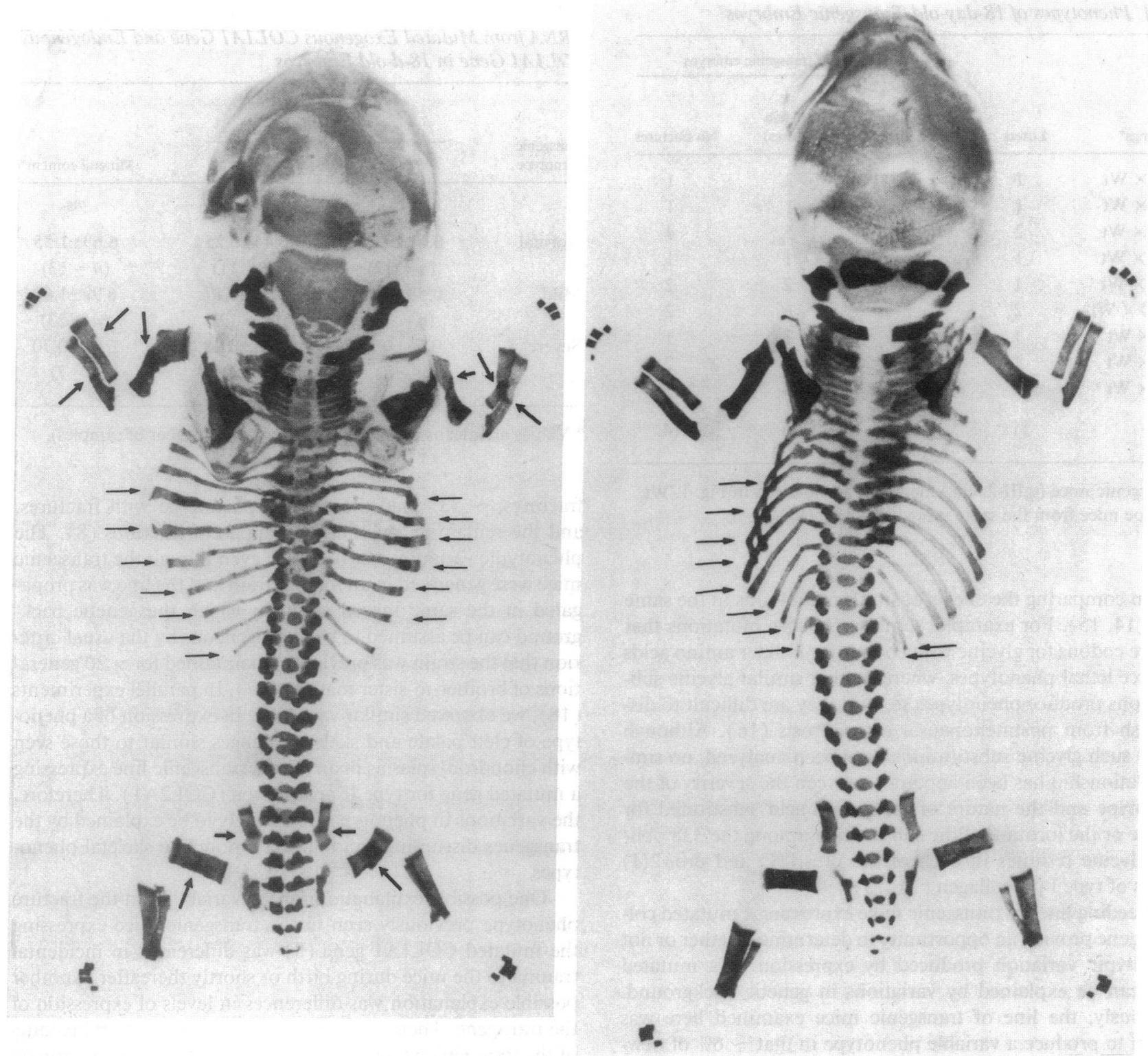

Figure 2. Stained skeletons from 18-d-old transgenic embryos. (Left) Embryo with fractures of both ribs and long bones. (Right) Embryo with fractures of ribs only.

Previous experiments (8) demonstrated that the mineral content of femurs from 6-wk-old transgenic mice of the line was reduced to $68 \%$ of the values for control littermate $(P$ $<0.01)$. Here, the same skeletons used to evaluate the phenotype were subsequently assayed for mineral content. There were no significant differences between embryos with no fractures, those with the mild phenotype, and those with the severe phenotype (Table II). The standard deviations for the mean values, however, were relatively large.

Effect of uterine position. One possible explanation for the variability in phenotype was the uterine position of the embryos. Therefore, the severity of the phenotype was examined as a function of whether the embryos were at the tip of the uterine horn, in the middle, or near the base. As indicated in Table III, there was only a slight effect of uterine position. Embryos with the mild and severe phenotypes were about equally distributed in the uterine horns. Embryos with a nor- mal phenotype were located primarily at the base and lower regions of the uterus.

\section{Discussion}

Phenotypic variation and incomplete penetrance in transmission of monogenic diseases present perplexing problems in dealing with the molecular etiology of human diseases. When encountered within families, they also present difficult problems in genetic counseling. In osteogenesis imperfecta, marked phenotypic variation has been seen among affected members of some families $(5,6)$. The phenotype variability reported in families with osteogenesis imperfecta is generally less than seen here with transgenic mice, but data are available only on a limited number of very large families, and most parents of children with severe forms of the disease elect not to have additional children. Also, marked phenotypic variation has been 
Table I. Phenotypes of 18-day-old Transgenic Embryos

\begin{tabular}{|c|c|c|c|c|}
\hline \multirow[b]{2}{*}{ Matings* } & \multirow[b]{2}{*}{ Litters } & \multicolumn{3}{|c|}{ Phenotypes of transgenic embryos } \\
\hline & & $\begin{array}{c}\text { Severe } \\
\text { (limb and } \\
\text { rib fractures) }\end{array}$ & $\begin{array}{l}\text { Mild (rib } \\
\text { fractures) }\end{array}$ & No fractures \\
\hline $\operatorname{tgIII}-2 \times \mathrm{Wt}$ & 1 & & 2 & 1 \\
\hline $\operatorname{tgIII}-4 \times W t$ & 1 & 1 & 1 & 1 \\
\hline $\operatorname{tgIV}-2 \times W t$ & 2 & 4 & 5 & 4 \\
\hline $\operatorname{tgIV}-5 \times W t$ & 1 & & 1 & 1 \\
\hline $\operatorname{tgIV}-7 \times W t$ & 1 & 2 & 2 & 2 \\
\hline $\operatorname{tgIV}-10 \times W t$ & 2 & 2 & 6 & 2 \\
\hline $\operatorname{tgV}-2 \times W t$ & 1 & 1 & 3 & 1 \\
\hline $\operatorname{tgV}-3 \times W t$ & 1 & & 2 & 2 \\
\hline $\operatorname{tgV}-6 \times W t$ & 1 & 1 & 4 & \\
\hline Totals & 11 & 11 & 26 & 14 \\
\hline
\end{tabular}

* Transgenic mice (tgIII-2, etc.) identified as indicated in Fig. 1. Wt, wild type mice from the same inbred strain (FVB/N).

seen in comparing the effects of similar mutations in the same gene $(14,15)$. For example, some single-base mutations that replace codons for glycine with codons for bulkier amino acids produce lethal phenotypes, whereas other similar glycine substitutions produce phenotypes so mild they are difficult to distinguish from postmenopausal osteoporosis (16). Although $>150$ such glycine substitutions have been analyzed, no simple relationship has been apparent between the severity of the phenotype and the nature of the amino acid substituted for glycine or the location of the substitution among the 338 obligate glycine residues in each of the pro 1 (I) and pro 2 (I) chains of type I procollagen $(14,15)$.

Breeding lines of transgenic mice expressing a mutated collagen gene provide an opportunity to determine whether or not phenotypic variation produced by expression of a mutated gene can be explained by variations in genetic background. Previously, the line of transgenic mice examined here was shown to produce a variable phenotype in that $\sim 6 \%$ of newborn transgenic pups had a lethal phenotype with extensive

\section{Transgenic $\underline{\underline{C}} \underline{\underline{S}} \underline{\underline{M}} \underline{\underline{S}}$

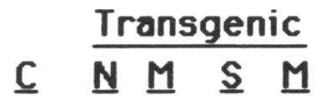

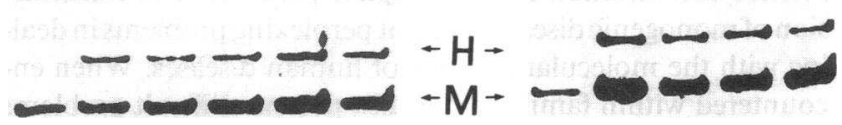

Figure 3. Assay of expression of the transgene and the endogenous gene for pro $\alpha 1$ (I) chains of type I procollagen. The assay was carried out by a quantitative RT-PCR assay described in the text. Results from two independent experiments are presented. $C$, control mouse; $N$, transgenic embryo with normal phenotype; $S$, transgenic embryo with a severe phenotype; $M$, transgenic embryo with a mild phenotype; $H$, fragment from the human transgene; $M$, fragment from the endogenous mouse gene.
Table II. Bone Mineral Content and Steady-State Levels of mRNA from Mutated Exogenous COL1A1 Gene and Endogenous COL1A1 Gene in 18-d-old Embryos

\begin{tabular}{lccc}
\hline & \multicolumn{2}{c}{$\begin{array}{c}\text { Ratio of mRNAs } \\
\text { (exogenous/endogenous)* }\end{array}$} & \\
\cline { 2 - 3 } $\begin{array}{c}\text { Transgenic } \\
\text { phenotype }\end{array}$ & Tail & Skin & Mineral content* \\
\hline & & & $m g$ \\
Normal & $0.61 \pm 0.20$ & $0.44 \pm 0.25$ & $6.69 \pm 1.55$ \\
& $(n=12)$ & $(n=11)$ & $(n=13)$ \\
Mild & $0.58 \pm 0.19$ & $0.36 \pm 0.17$ & $6.99 \pm 1.60$ \\
& $(n=13)$ & $(n=12)$ & $(n=23)$ \\
Severe & $0.55 \pm 0.12$ & $0.51 \pm 0.28$ & $6.01 \pm 0.70$ \\
& $(n=7)$ & $(n=6)$ & $(n=7)$ \\
& & & \\
\hline
\end{tabular}

* Values are means \pm standard deviation ( $n=$ number of samples).

fractures, $\sim 33 \%$ had a moderate phenotype with fractures, and the remaining mice had no apparent fractures (8). The phenotypic variation was observed even though the transgenic mice were generated in an inbred strain and the line was propagated in the same inbred strain in which the genetic background can be assumed to be homogeneous by the usual criterion that the strain was previously maintained for $>20$ generations of brother-to-sister matings (17). In parallel experiments (18), we observed similar variability in expression of a phenotype of cleft palate and skeletal changes similar to those seen with chondrodysplasias in an inbred transgenic line expressing a mutated gene for type II procollagen (COL2A1). Therefore, the variations in phenotype are unlikely to be explained by the transgenes disrupting loci that may modulate skeletal phenotypes.

One possible explanation for the variability in the fracture phenotype previously seen in the transgenic mice expressing the mutated COL1Al gene (8) was differences in incidental trauma to the mice during birth or shortly thereafter. Another possible explanation was differences in levels of expression of the transgene. Therefore, here we carried out further breeding of the transgenic mice in the same inbred strain and examined embryos by caesarian section. The results demonstrated that the same phenotypic variation was present in 18-d-old embryos. About one-fifth of the embryos had a severe phenotype with extensive fractures of long bones and ribs. About half had

Table III. Effect of Uterine Position on Phenotype

\begin{tabular}{|c|c|c|c|c|c|c|}
\hline \multirow{3}{*}{$\begin{array}{l}\text { Transgenic } \\
\text { phenotype }\end{array}$} & \multicolumn{6}{|c|}{ Uterine position* } \\
\hline & \multicolumn{2}{|c|}{ Base } & \multicolumn{4}{|c|}{ Above the base } \\
\hline & 1 & 2 & 3 & 4 & 5 & 6 \\
\hline Normal & 5 & 4 & 3 & 1 & & \\
\hline Mild & 4 & 4 & 8 & 3 & 7 & \\
\hline Severe & 2 & 1 & 3 & 1 & 2 & 2 \\
\hline
\end{tabular}

* Embryos removed by the cesarean section were scored for phenotype (Table I) and uterine position. The positions of embryos in the uterus were numbered from the lowest position in the uterus to the tip. The size of the litters varied from 5 to 12 with mean of $9.82 \pm 1.99 \mathrm{SD}$. 
a mild phenotype with fractures only in ribs, and the remaining mice had no fractures. The phenotypic variation was not explained by variations in the level of expression of the transgene in the mice. As assayed by a quantitative RT-PCR method, the level of expression was the same in embryos with the severe phenotype, embryos with the mild phenotype, and embryos with a normal phenotype. Also, there was only a slight effect of uterine position on the severity of the phenotype in that embryos with a normal phenotype were found primarily in the base and the lower portion of the uterine horn, but embryos with the mild and severe phenotypes were about equally distributed.

The variations in phenotype observed here may have been determined by subtle differences in micro-environment that were not related by the position of the embryos in the uterus. Alternatively, they may have been determined by stochastic events during embryonic development that were not related to the micro-environment. For example, stochastic events may have produced variations in expression of both the endogenous gene and mini-gene in some embryos without altering the mineral content of bone. Regardless of the molecular mechanisms, however, the results indicated that variability in phenotype was an inherent feature of expression of the mutated collagen gene even in a homogeneous genetic background. The observations, therefore, may be an important consideration in counseling families with osteogenesis imperfecta, particularly families in which the first affected member has a mild phenotype.

\section{Acknowledgments}

Supported in part by grants from N.I.H. (AR-38188), the March of Dimes/Birth Defect Foundation, and the Lucille P. Markey Charitable Trust.

\section{References}

1. Lalouel, J. M., and R. White. 1990. Analysis of Genetic Linkage. In Principles and Practice of Medical Genetics, Vol. 1. A. E. H. Emery, D. L. Rimoin, J. A. Sofaer, I. Black, and V. A. McKusick, editors. Churchill-Livingston Inc., New York. 149-164.

2. Ott, J. 1991. Penetrance. In Analysis of Human Genetic Linkage. Revised Edition. The Johns Hopkins University Press, Baltimore. 146-164.

3. Han, M., R. V. Aroian, and P. W. Sternberg. 1990. The let-60 locus controls the switch between vulval and nonvulval cell fates in Caenorhabditis elegans. Genetics. 126:899-913.

4. Hedgecock, E. M., J. G. Culotti, and D. H. Hall. 1990. The unc-5, unc-6, and unc- 40 genes guide circumferential migrations of pioneer axons and mesodermal cells on the epidermis in C. elegans. Neuron. 4:61-85.

5. de Vries, W. N., and W. J. de Wet. 1987. Cysteine in $\alpha 1$ chains of human type I collagen produces a clinical heterogeneous form of osteogenesis imperfecta.

In UCLA Symposium on Molecular Biology and Cellular Biology: New Series, Vol 46. A. Sen, and T. Thornhill, editors. Liss, New York. 56-64.

6. Sippola, M., S. Kaffe, and D. J. Prockop. 1984. A heterozygous defect for structurally altered pro 2 chains of type I procollagen in a mild variant of osteogenesis imperfecta. The altered structure decreases the thermal stability of procollagen and makes it resistant to procollagen N-proteinase. J. Biol. Chem. 259:14094-14100.

7. Khillan, J. S., A. S. Olsen, S. Kontusaari, B. Sokolov, and D. J. Prockop. 1991. Transgenic mice that express a mini-gene version of the human gene for type I procollagen (COL1A I) develop a phenotype resembling a lethal form of osteogenesis imperfecta. J. Biol. Chem. 266:23373-23379.

8. Pereira, R., J. S. Khillan, H. J. Helminen, E. L. Hume, and D. J. Prockop. 1993. Transgenic mice expressing a partially deleted gene for type I procollagen (COL1A1). A breeding line with a phenotype of spontaneous fractures and decreased bone collagen and mineral. J. Clin. Invest. 91:709-716.

9. Olsen, A. S., A. E. Geddis, and D. J. Prockop. 1991. High levels of expression of a minigene version of the human proal (I) collagen gene in stably transfected mouse fibroblasts. Effects of deleting putative regulatory sequences in the first intron. J. Biol. Chem. 266:1117-1121.

10. Peters, P. W. J. 1977. Double staining of fetal skeletons for cartilage and bone. In Methods in Prenatal Toxicology. D. Neubert, H.-J. Merker, and T. E. Kwasigroch, editors. Georg Thieme Verlag, Stuttgart. 153-154.

11. Chomzynski, P., and N. Sacchi. 1987. Single-step method of RNA isolation by acid guanidinium thiocyanate-phenol-chloroform extraction. Anal. Biochem. 162:156-159.

12. Sokolov, B. P., P. K. Mays, J. S. Khillan, and D. J. Prockop. 1993. Tissueand development-specific expression in transgenic mice in the type I procollagen (COL1A 1) mini-gene construct with $2.3 \mathrm{~kb}$ of the promoter region and $2 \mathrm{~kb}$ of the 3 '-flanking region. Specificity is independent of putative regulatory sequences of the first intron. Biochemistry. 32:9242-9249.

13. Cassella, J. P., R. Pereira, J. S. Khillan, D. J. Prockop, N. Garrington, and S. Y. Ali. 1994. An ultrastructural, microanalytical and spectroscopic study of a transgenic mouse model for osteogenesis imperfecta. J. Bone. In press.

14. Kuivaniemi, H., G. Tromp, and D. J. Prockop. 1991. Mutations in collagen genes: causes of rare and some common diseases in humans. FASEB (Fed. Am. Soc. Exp. Biol.) J. 5:2052-2060.

15. Byers, P. H., G. A. Wallis, and M. C. Willing. 1991. Osteogenesis imperfecta: translation of mutation into phenotype. J. Med. Genet. 28:433-442.

16. Spotila, L. D., C. D. Constantinos, L. Sereda, A. Ganguly, B. L. Riggs, and D. J. Prockop. 1991. Mutations in the gene for type I procollagen (COL1 A2) in a woman with post-menopausal osteoporosis: evidence for a phenotypic and genotypic overlap with mild osteogenesis imperfecta. Proc. Natl. Acad. Sci. USA. 88:5423-5427.

17. Hogan, B., F. Constantini, and E. Lacy. 1986. Manipulating the Mouse Embryo: A Laboratory Manual. Cold Spring Harbor Laboratory, Cold Spring Harbor, NY. 7 pp.

18. Helminen, H. J., K. Kiraly, A. Pelttari, M. I. Tammi, P. Vandenberg, R. Pereira, R. Dhulipala, J. S. Khillan, L. Ala-Kokko, E. L. Hume, B. P. Sokolov, and D. J. Prockop. 1993. An inbred line of transgenic mice expressing an internally deleted gene for type II procollagen (COL2A 1 ). Young mice have a variable phenotype of a chondrodysplasia and older mice have osteoarthritic changes in joints. J. Clin. Invest. 92:582-595. 